\title{
Síndrome de Jervell y Lange-Nielsen
}

\author{
Jervell and Lange-Nielsen Syndrome
}

Silvia Borkoski B, Daniel Pérez P, Juan Carlos Falcón G, Ángel Ramos M.

\begin{abstract}
RESUMEN
El síndrome de Jervell y Lange-Nielsen es una forma poco frecuente de síndrome de QT largo. Su herencia es autosómica recesiva y se manifiesta con sordera neurosensorial. Revisamos el caso de una niña de 7 años implantada coclear bilateral. Tras un episodio sincopal se realiza el diagnóstico de síndrome de QT largo, el estudio genético confirma el diagnóstico. Recomendamos realizar electrocardiograma a todos los niños con hipoacusia severa con el objeto de descartar este síndrome.
\end{abstract}

Palabras clave: Síndrome de QT largo, síndrome de Jervell y Lange-Nielsen.

\begin{abstract}
The Jervell and Lange-Nielsen (JLNS) is an uncommon form of long QT syndrome. His inheritance is autosomal recessive and manifests as a sensorineural deafness. We review the case of a 7 year old girl bilateral cochlear implanted. After a syncope episode, a long QT syndrome was confirmed by genetic study. We recommend electrocardiogram (ECG) to all children with severe hearing loss in order to rule out this syndrome.
\end{abstract}

Key words: Long QT syndrome, Jervell and Lange-Nielsen Syndrome.

\section{INTRODUCCIÓN}

El síndrome de QT largo es una enfermedad hereditaria arritmogénica. Existen dos formas: el síndrome autosómico dominante Romano-Ward y la forma autosómica recesiva Jervell Lange-Nielsen (JLNS), síndrome asociado con sordera neuro-sensorial ${ }^{1,2}$. En el JLNS la incidencia estimada es de 1,6-6 casos por millón ${ }^{3,4}$. La prolongación del intervalo QT se asocia con taquiarritmias torsade de pointes, incluyendo taquicardia ventricular y fibrilación ventricular, que puede terminar con síncope o muerte súbita. La deficiencia de hierro (anemia) y niveles elevados de gastrina también son características frecuentes del JLNS ${ }^{5}$. La presentación clásica del JLNS es un niño sordo que experimenta episodios sincopales recurrentes durante períodos de estrés, el ejercicio 0 el miedo, convulsiones o muerte súbita ${ }^{6}$. El cincuenta por ciento de las personas con JLNS han presentado eventos cardíacos antes de la edad de tres años. Más de la mitad de los niños no tratados con JLNS pueden morir antes de los 15 años $^{7,8}$. El diagnóstico se establece en un niño con sordera congénita neurosensorial, intervalo QT largo, y la presencia de mutaciones heterocigotas u homocigotas en los genes KCNQ1 o KCNE1, genes que codifican para canales de sodio y potasio $0^{9-11}$.

Presentamos el caso de una niña con diagnóstico de JLNS que fue implantada en forma bilateral.

- Unidad de Hipoacusia, Servicio de ORL y PCF Complejo Hospitalario Universitario Insular-Materno Infantil.

Las Palmas de Gran Canaria. España. 


\section{CASO CLÍNICO}

Paciente de 7 años, hija de padres consanguíneos. La menor de cuatro hermanos; implantada coclear de manera bilateral simultánea a los 17 meses sin eventos adversos durante la cirugía. La anatomía del oído es normal confirmado mediante estudio de imágenes (tomografía computarizada de oído). Buena adquisición del lenguaje, la paciente es bilingüe (árabe-español). Como antecedente familiar de importancia destacar que uno de sus hermanos también implantado coclear, falleció por muerte súbita a los 9 años de edad. La paciente fue diagnosticada de anemia microcítica hipocrómica a los 6 años de edad. En diciembre de 2011 presentó cuadro sincopal con traumatismo encéfalo craneal (TEC). En julio de 2012, sufrió segundo episodio sincopal, durante la realización de actividad física en el colegio. Al ingreso cardiología informó un electrocardiograma (ECG) con ritmo sinusal 81 latidos por minuto (Ipm) y un QT 420 ms y corregido $490 \mathrm{~ms}$, onda T de base amplia asimétrica mellada en precordiales derechas (Figura 1). Ecocardiograma normal. Ante la sospecha de síndrome de QT largo se realiza estudio genético a partir de sangre periférica donde se confirma la presencia en homocigosis de la mutación p.Glu261Serfs*2 (cambio en la codificación, Glutamina por Serina, que da origen a una proteína truncada) en el gen KCNQ1 compatible con el fenotipo del paciente y con el diagnóstico de síndrome de JLNS. También presenta heterocigosis en la variante p.Gly852Arg (cambio en la codificación, Glicina por Arginina) en el gen KCNG2, esta variante ha sido descrita como de patogenicidad incierta y puede tratarse de un polimorfismo sin actividad sobre el fenotipo de la paciente. Actualmente la paciente se encuentra en tratamiento farmacológico con beta bloqueantes (propanolol dosis de 1,8 mg/kg/día) sin haber padecido otro episodio sincopal y control hematológico por su anemia.

\section{DISCUSIÓN}

El síndrome de QT largo debe ser considerado como posible diagnóstico en niños y adultos jóvenes con síncope de origen desconocido, arritmia ventricular y convulsiones no febriles, especialmente durante esfuerzo físico 0 agitación emocional.

La incidencia del JLNS es $<10 \%$ del total de casos de síndrome de QT largo, se estima en 6 de cada 1.000 individuos sordos congénitos ${ }^{8}$. Es la forma más severa de las diferentes variantes del síndrome de QT largo. Los pacientes presentan una hipoacusia neurosensorial severo-profunda, asociada a eventos arrítmicos ventriculares, especialmente torsade de pointes.

La deficiencia en el oído está limitada a la cóclea, existe marcada atrofia de la estría vascular, colapso de los compartimentos endolinfáticos y degeneración completa del órgano de Corti. No existe disfunción vestibular y la estructura coclear es normal' ${ }^{12}$.

Entre los pacientes con JLNS, el 15\% se tornan sintomáticos dentro de los primeros 23 meses de

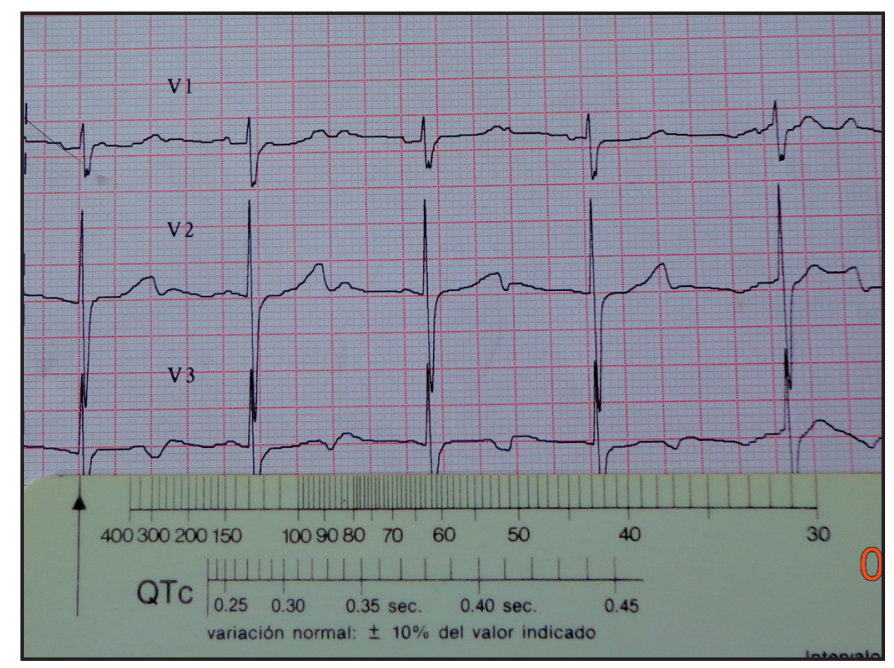

Figura 1. ECG realizado durante el ingreso, QT $443 \mathrm{~ms}$ y corregido QTc $453 \mathrm{~ms}$. 
vida y antes de los 18 años el $90 \%$ ha tenido un primer evento cardíaco.

El ejercicio y las situaciones de estrés son condiciones asociadas con el aumento de la actividad simpática, y representan el $95 \%$ de eventos cardiacos. Solamente en $5 \%$ el evento se asocia con el reposo o el sueño ${ }^{9}$.

Algunos casos JLNS pueden ser asintomátios, por lo que es importante tenerlo en cuenta ante el diagnóstico de sordera neurosensorial profunda en pacientes con resultados anormales en ECG, ritmo cardíaco lento, intervalo QT prolongado, y arritmia ventricular.

El tratamiento recomendado son los bloqueadores betaadrenérgicos que han demostrado reducir significativamente la mortalidad, de $50 \%$ a $<5 \%$, entre los pacientes sintomáticos. Se recomienda que Ios pacientes con JLNS tomen la dosis máxima tolerada de betabloqueantes a lo largo de sus vidas, en pacientes asintomáticos también es recomendable para proteger ante la posibilidad de muerte súbita en el momento del primer evento, así como para reducir la posibilidad de eventos cardíacos en el futuro ${ }^{12}$.

Queremos destacar la importancia de que en niños con sordera congénita se debe tener presente este síndrome y solicitar un ECG de forma sistemática con el fin de detectarlo, y en particular, en caso de la implantación coclear antes de la anestesia. Aunque la presencia de este síndrome plantea problemas adicionales para el equipo de implante coclear, la implantación puede realizarse de manera segura, si se toman las precauciones apropiadas.

Es recomendable que los miembros de la familia del paciente con JLNS sean examinados cardiológicamente para detectar el síndrome de QT largo, incluso si tienen una audición normal.

\section{BIBLIOGRAFÍA}

1. Jervell A, Lange-Nielsen F. Congenital deafmutism, functional heart disease with prolongation of QT interval and sudden death. Am Heart J 1957; 54: 59-69.

2. Kass RS, Moss AJ. Long QT syndrome: novel insights into the mechanisms of cardiac arrhythmias. J Clin Invest 2003; 112(6): 810-5.

3. GR Fraser, P Froggatt, TN James. Congenital deafness associated with electrocardiographic abnormalities, fainting attacks and sudden death. A recessive syndrome. Quart J Med 1964; 33: 361-85.

4. Splawski I, Timothy KW, Vincent GM, Atkinson DL, Keating MD. Molecular basis of the long-QT syndrome associated with deafness. Proc Asoc Am Physicians 1997; 109(5): 504-11.

5. Winbo A, Sandström 0, Palmqvist R, Rydberg A. Iron-deficiency anemia, gastric hyperplasia, and elevated gastrin levels due to potassium channel dysfunction in the Jervell and Lange-Nielsen Syndrome. Cardil Young 2012; 18: 1-10.

6. Sathyamurthy I, Jayanthi K, Dash J, SRinivasan KN. Long QT Syndrome in children with congenital deafness. Indian Pediatrics 2009; 46(6): 507-8.

7. Tranebjaerg L, Samson RA, Green GE. Jervel and Lange- Nielsen Syndrome in: Pagon RA, Bird TD, Dolan CR, et al., editors. Gene Reviews $^{\mathrm{TM}}$ [internet]. Seattle (WA): University of Washington, Seattle; 1993.

8. Belmont JW, Craigen WJ, Martínez H, Jefferies JL. Genetic disorders with both hearing loss and cardiovascular abnormalities. Adv Otorhinolaryngol 2011; 70: 66-74.

9. Schwartz PJ, Spazzolini C, Crotti L, Bathen J, Amlie JP, Tімотну K, eт AL. The Jervell and Lange-Nielsen syndrome: natural history, molecular basis, and clinical outcome. Circulation 2006; 113: 783-790.

10. Splawski I, Shen J, Timothy KW, Lehmann MH, Priori S, Robinson JL, Moss AJ, Schwartz PJ, Towbin JA, VICENT GM, KEATING MT. Spectrum of mutations in long-QT syndrome genes. KVLQT1, HERG, SCN5A, KCNE1, and KCNE2. Circulation 2000; 102(10): 1178-85.

11. Denjoy I, Lupoglazoff JM, Villain E, Vaksmann G, Godart F, Lucet V, Leenhardt A, Guicheney P, Schwartz P. Syndrome De Jervell et Lange Nielsen. Historie naturelle, bases moléculaires et devenir Chinique. Archives des Maladies du coeur et des vaisseaux. 2007, tome 100, $n^{0} 5$.

12. Feng Yanmel, WU Yaqin, Shi Haibo, Zhou Huiqun, Chen Zhengnong, Yu Dongzhen, Yin Shangai. Cochlear implantation in patients Jervell and Lange- Nielsen syndrome, and a review of literature. International Journal of Paediatric Otorhinolaryngology 2008; 72: 1723-9.

Dirección: Silvia Borkoski B.

Servicio de ORL y PCF Complejo Hospitalario Universitario Insular-Materno Infantil Las Palmas de Gran Canaria, España

E mail: silviaborkoski@hotmail.com 